\title{
Development of the Method of Formation of the Architecture of the Innovation Program in the System "University-State-Business"
}

\author{
Varvara Piterska $^{1 *}$, Sergey Rudenko ${ }^{1}$, Anatoliy Shakhov ${ }^{1}$ \\ ${ }^{I}$ Odessa National Maritime University \\ *Corresponding author E-mail: onmukafedra@gmail.com
}

\begin{abstract}
We investigated the mechanisms of increase of efficiency of innovative activity on the basis of methodology of management of projects and programs of sustainable development on the basis of the GPM Global P5 standard as well as the triple helix model "UniversityState-Business". This method takes into account the current trends of program and project management of innovation. The mechanism of target distribution for universities 1.0, 2.0, 3.0, 4.0 is investigated. Suggested model of the innovation program management is based on the model of the triple helix interaction and allows to take into account the interests of all groups of stakeholders. The mechanism of formation of the mission of the innovation program, which allows to determine the strategic goals of the innovation program participants, namely - the competitiveness of the University for higher education institutions, the quality of life of the population for the state and the profit for business. The method of formation of the architecture of the innovation program in the system "University-State-Business" has been developed with the integration of the interests of all participants of the program. The method of creating an office of management of the innovation program is proposed taking into account the model of the architecture of the innovation program.
\end{abstract}

Keywords: Architecture of Program; Innovation Program; Mission; Project Management; Triple Helix Model.

\section{Introduction}

International practice of research in the field of development of effective concepts of public administration proves that the main driver of socio-economic development of society is innovative activity.

Over the last decades, Ukrainian science has changed significantly. Some time ago being one of the leading countries in the world with numerous schools, traditions, material and technical bases, Ukraine has come to a state in which all attempts to increase the efficiency of innovation activities end in decline.

However, a simple increase in funding will not lead to results. Historically, the system of financing science in Ukraine is built in such a way that the state finances utility payments of research institutes and pays meager salaries to workers.

An example of business incubators that have proven to be effective and innovative organizations is the Cambridge Technopark and Silicon Valley Technopolis. Foreign regions are dynamically developing innovative activity on the model of the triple helix. In Ukraine, unfortunately, except for the slogans that the need to create and implement innovations in all spheres of society, in practice, attempts to transition to an innovative way of development end in failure. All known global approaches to innovation management in Ukraine are not implemented.

The relevance of the study is due to the modern unpleasant innovative climate in the state, which is formed in the conditions of non-operating state regulation of the innovation sphere, the rapid decline of Ukrainian science, its actual appearance from entrepreneurship. In such situation, there is an urgent need to develop new theoretical and methodological approaches and mechanisms that would enhance the effectiveness of the interaction of all innovation actors on the basis of the best practices of developed countries.

\section{Literature Review and Problem Statement}

Current international trends indicate the importance of developing a new methodology for sustainable project-oriented management of organizations based on the "Iron Triangle", which is harmonized with the social, economic, environmental aspects as factors in the project environment (Fig 1) [1].

According to [1] there are 17 targets in the area of sustainable human development until 2030, which should be considered in the product development project.

The goals given in [1] can be divided into the following levels.

The level of the state determines the eradication of poverty and hunger, good health and well-being of the population, gender equality, industry, innovation, infrastructure. It also takes into account the sustainability of cities and human settlements, climate change, the preservation of marine and terrestrial ecosystems, peace, justice and effective institutions.

At the university level are expected quality education, innovation and infrastructure.

The level of business structures includes low-cost and clean energy, industrialization, innovation, infrastructure, decent work and economic growth, responsible consumption and production. 


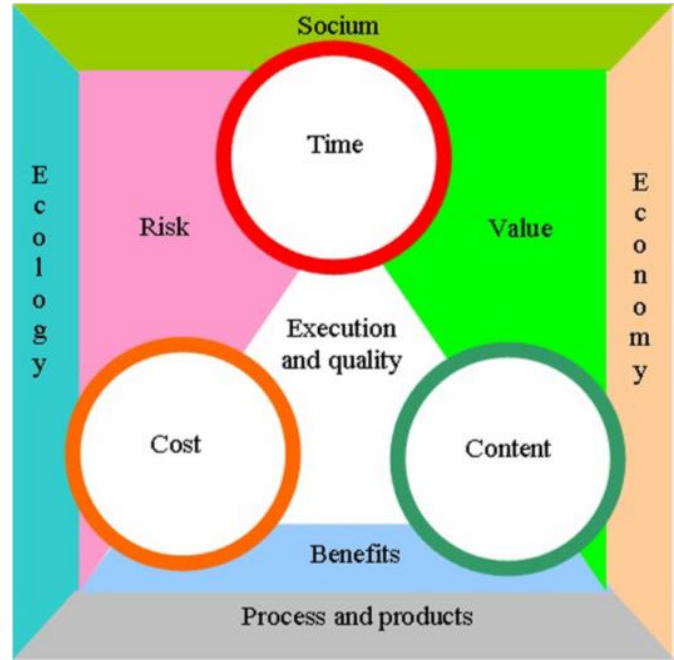

Fig. 1: "Iron Triangle" of the Project and its Environment [1]

The international community has set partnership for sustainable development as the main goal of the organizations that manage projects and programs.

Modern global approaches to innovation management cause radical transformations associated with the decisive importance of universities for innovative development, which leads to economic growth of the state, improving the welfare of the population and supporting business.

At the international level, there is a change in the goals of universities - in addition to scientific and educational, there is a goal of economic activity. This goal includes the development and transfer of technologies, commercialization of academic science products, management of intellectual property in order to make a profit, the creation of new business structures. Depending on the number of goals, higher education institutions are divided into: University $1.0,2.0,3.0,4.0$. University 1.0 is only an educational institution. University 2.0 provides educational services and conducts scientific research. The University's 3.0 goal is educational, scientific activities and commercialization of knowledge (innovation). The University 4.0 is specialized in carrying out educational, scientific, innovative activities, as well as the formation of the creative environment [2].

The most promising from the point of view of innovative development is the model "University 4.0". This model allows, in addition to the training of professional specialists capable of solving problems on the basis of blockchain technology, to form a progressive environment of knowledge and innovation, which will allow to obtain an effective result from the implementation of innovative activities.

In this case, the University is positioned as a corporate subject of the knowledge economy [2]. For Ukraine, the problem of expanding the goals of the University is socially significant, because it is the transfer of technology and commercialization of knowledge through the implementation of the product of innovation today plays a crucial role in the modernization of the socio-economic situation of the state.

Ukraine in the world competitiveness ranking among 142 countries fell to 81 place, behind Kenya and Botswana, and in the innovation ranking -71 place [3]. This strategic assessment includes the following indicators: 87 th place in the field of effective management, 98 - in the degree of infrastructure development, $101-$ in the quality of regulatory support and the feedback of politicians to the problems of science and innovation development [3]. And only the 30th place on the results of scientific research and the 37 th place on the quality of human capital allowed Ukraine not the lowest part of the rating [3].

Every year can be traced to the decrease of all parameters, including the main of them - the specific weight of sales of innovative products in the total volume of industrial production: $7 \%$ in 2005 [3], $4.8 \%$ in 2012 [3] and $3.8 \%$ in 2017 [3] show that the state does not have a transition to an innovative path of development. In Ukraine, 10 thousand workers account for only 43 employed in science, while in Germany - 124, in France - 135, in Denmark 143, in Finland - 154, in the US - 97, in South Korea - 95, in Japan - 110 [3].

In 2017 , spending on science was only $0.24 \%$ of GDP [3]. In the European Union, under the Lisbon strategy, such costs are maintained at 3 per cent of GDP and the average research expenditure per person per month is $€ 473$ [4]. In Ukraine, this figure is only 19 euros [3].

Methodological bases of management of innovative projects and programs are presented in the works of famous scientists. Research conducted in [5], concerning the creation of high-tech enterprises that are actively involved in the innovative development of the state. The paper [6] presents a model of harmonization of values of development programs of organizations in a turbulent environment. The concept of selection and formalization of the project for the lack of complete information is presented in [7]. The creative technologies proposed in [8] in program management can improve the efficiency of program-based management of innovation. The issue of expansion of national industrial competitiveness on the basis of innovative programs is considered in [9]. Methodological bases of management of innovative projectoriented organizations are presented in [10]. The use of the project-oriented approach in innovation activities are given in [11]. The energy value management model of the project-oriented organization was developed in [12]. In [13] proposed a mechanism for the management of the external environment of the project which gives the opportunity to exercise control over action of interested parties in obtaining an innovative product. The models of the innovation process and the consequences of their application are presented in [14]. The study of the triple helix of innovation is devoted to the work [15].

However, at present there are no studies on the organization of the process of interaction and distribution of responsibility for the results at each stage of the innovation program between all stakeholders. In modern conditions, it is not difficult to see that the initiated innovative developments end at the University level. The problem is that any, even at first glance, attractive results of scientific research remain unclaimed. Thus, at the stage of the final report from the applied developments, the innovation activity is stopped. The result of the scientific work is only a document, the use of which in most cases does not provide an opportunity to obtain socio-economic effect from the development and implementation of the product innovation. This is due to the lack of interest of business in the acquisition of patented ideas of the University, teaching a large risk of losses. As for the state, that, at the initial stage, financing the research work of the University, it also loses from the spent money for the budgeting of scientific research which then become unclaimed on the market.

This situation is based on two main reasons - economic (insufficient financing from the state) and organizational (inefficient management of public institutions).

\section{The Aim and Objectives of the Study}

The aim of the study is to develop scientifically based mechanisms of innovation management based on the methodology of project and program management based on the standard of sustainable development GPM Global P5 within the triple helix system "University-State-Business"

To achieve this goal, the following tasks were set:

- to clarify the definitions of the innovative program and to develop scientific proposals for the application of program-target approach to solving the problem of reforming the processes of innovation management;

- to develop a method of formation of the architecture of the innovation program in the triple helix system "University-StateBusiness" taking into account the interests of all performers; 
- to offer a method of creating an office of management of an innovative program based on the innovative architecture of the program.

\section{Materials and Methods of the Innovation Program Management in the System "Uni- versity-State-Business"}

The methodology of project and program management allows us to formulate the concept of innovation as a program that includes a set of projects united by a single mission - to obtain a socioeconomic effect from the implementation of an innovative product The innovation program may include the following types of projects: fundamental and applied research, project and development, experimental production, marketing research, advertising, etc. The innovation program is a strategic form of activity of organizations designed to create value, which implies the mission of the program.

The structure of the innovation program is defined in detail in the document that describes the concept of the program and the group of projects that make up it.

Management of the innovation program is the process of direct influence on the system of innovative activity taking into account organizational, economic and psychological and social methods, forms and methods of obtaining innovations. The result of management is the achievement of order, sustainability and development of the innovation system in accordance with the goals. The system of management of innovation program includes a set of interrelated elements - government bodies, university, businesses that consistently perform innovation activities to achieve a common mission.

Let us present the life cycle of innovation development management and show the main results (products), which are the result of each phase of the innovation program (Fig. 2).

All decisions made in the management of the innovation program are based on the evaluation of the value of the program, determined by its mission. The evaluation is carried out at all stages of the program life cycle.

The mission of the innovation program is developing in perfect scenes through the interpretation of the content of the mission of the program in the most effective direction, with the use of the development of the value structure for the transformation of organizations participating in the program from the current state to the "desired" state.

A special feature of the innovation program is the participation in its implementation of a great number of performers who pursue different goals. The challenge of effective management is to bring together the goals of all participants to achieve a single mission.

The existing best practices and mechanisms of management are not applied to the realities of the Ukrainian innovation. This prize leads to the isolation from each other of the elements of the system of implementation of the innovation program of the University, business and the state. Currently, each participant creates a separate control system, which is not associated with other participants in the innovation program. Such actions lead to a breakdown in the integrity of the innovation management system, which requires immediate action to ensure that the entire system is operational. There is a need to establish cooperation within the framework of a triple helix model that combines the efforts of science, production and various forms of government regulation. This approach has obvious advantages - science is experiencing the needs of production, the state implements incentive measures, business structures are dependent on the needs of the population in an innovative product.

This paradigm assumes that knowledge and technology arise as a result of the actions of higher education institutions, business structures and the state, which partially intersect with each other.
It also implies that knowledge and technology is then transferred to the economy, which is ultimately the main driver of innovation.

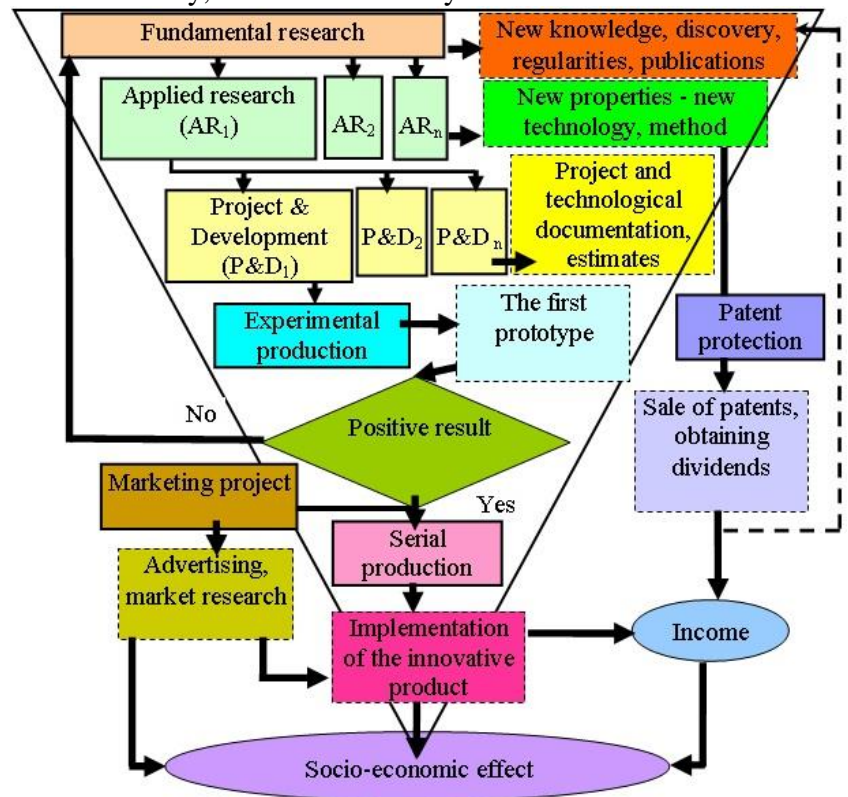

Fig. 2: Life Cycle of the Innovation Program: AR - applied research; P\&D - Project \& Development

One of the basic advantages of the presented model of interaction between the university, business and the state in the program management of innovation activities is to take into account the nature of the demand for innovation.

In modern conditions of inefficient management of innovative activities, it is important to move to the use of program management mechanisms. Currently, the management of innovation activities is carried out separately by each actor in the framework of the innovation project. In this case, each participant pursues its own goal without taking into account the consequences of its activities for the future, namely, it is meant to obtain an overall socioeconomic effect from the implementation of an innovative product. Nobody thinks about building relationships, able to form a cohesive system of innovative activity management with the single mission. It is proposed to combine the whole complex of works from the development of the idea to the implementation of innovative activity products into a single integrated program, even in the case when the execution of this project is carried out by various specialized organizations.

Projects within the innovation program are connected by a single result.

Taking into account the methodology of project and program management, it can be argued that the result of projects in the framework of innovation is the achievement of a single mission of the innovation program. The result of the innovation program is described through the formulation of the system of goals of all its participants.

Since innovation activities are carried out by various organizations, united by a common goal, the whole complex of innovative projects of all participants will be considered a program.

The management of the innovation program focuses on the strategic activities for the full implementation of the program's mission and the unification of the projects of the program participants, their strategies, the architecture of the program and the controls during the implementation of the program.

The management function of the innovation program is aimed at uniting the goals of the participants, formed from the mission of the program, the formation of a clear plan. Establishing cooperation between elements of the innovation program will encourage the organization to better respond to changes in the activities of this environment through planning, control, monitoring, coordination, analysis of alternatives and the initiation of possible at all stages of the innovation program. 
Fig. 3 proposed the model of management of innovation program, which illustrates the path of value creation through the program.

The management of the innovation program begins with the development of a mission that is approved by the program stakeholders. The process of determining the mission is the most important and focused on the mission statement of the program through problem identification and the formulation of the strategy. For effective management of the innovative program it is proposed to develop the program architecture. The creation of the program architecture will allow to take into account the interests of all stakeholders (University, business and the state) in the management of the program.

The management of the innovation program strategy is concerned with the establishment of the mission and the management of the program architecture. The mission of the innovation program is to transform into innovative products of unique value, due to the formation of the program architecture, planning and monitoring system, as well as the implementation of the actions for the implementation of the program.

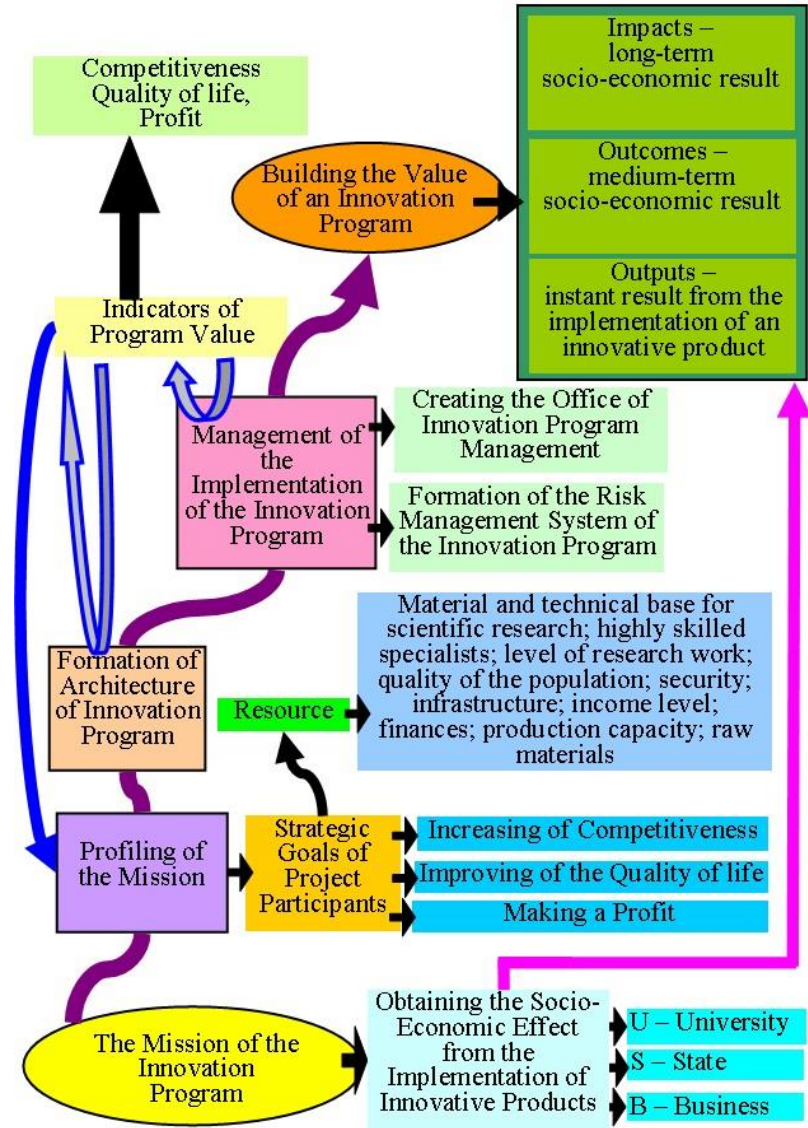

Fig. 3: Model of the Innovation Program Management

The main result of the innovation program is the achievement of a single mission to obtain socio-economic results as a result of the manufacture, implementation and use of innovative products.

The process of managing the architecture of the innovation program begins with the development of an exemplary structure aimed at achieving the mission of the program, taking into account the compensation of the impact of changes in the environment.

For government programs aimed at ensuring the priority of innovation, a characteristic feature is the focus on three types of results at the same time. The first are achieved immediately after the implementation of innovation (outputs). The latter are possible in the medium term (outcomes). Third are the consequences, i.e. longterm results (impacts).

Considering innovative programs, it is possible to note the big orientation on reception of social and economic results for society in the form of an innovative product in the medium-term prospect, that is "outcomes". This is due to the fact that after a long period of time innovative product may no longer be relevant due to the emergence of a more thorough innovation.

The proposed method of forming the architecture of the innovation program allows, in contrast to the existing management methods, to implement the separation of the strategic objectives of each participant of the triple helix system "U-S-B". The achievement of certain strategic goals by the participants of the innovation program changes the state of the object of management, which is characterized by an increase in the effectiveness of innovation in the implementation of a single mission of the innovation program.

\section{Results of the Application of the Mechanism for Determining of the Mission of the Inno- vation Program in "U-S-B" System}

The program is implemented through a group of innovative projects, which are its components. By developing and visualizing the structure of the program, stakeholders in the University-StateBusiness (U-S-B) triple helix system have a better understanding of their role in the program and their relationships with other participants. The parties shall determine the limits of their competence that can be applied to the implementation of a specific scope of work in the innovation program.

It is important to stress that the activities of the participants of the innovation program is aimed at achieving each participant of the innovation program individual strategic goal, which does not contradict the overall mission of the program.

As a strategic goal for business structures is to make a profit from the implementation of an innovative product.

If we consider the activities of the University, the key indicator of its activity is to improve competitiveness. There are dozens of ratings in the world regarding the definition of this indicator, however, at present there is no single methodological framework that would allow to take into account all aspects of the activity of higher education institutions. The paper [16] presents a practical model of image management of an educational institution.

In this research, when determining the competitiveness of the University of $K_{U}$ proposed to take into account certain indicators. Such indicators include the material and technical base, the level of qualification of scientific and pedagogical workers, the contingent of teachers, the number of scientific schools, prepared monographs, articles, received patents. The presented list can be expanded by each University taking into account its strategic goal, which does not contradict the common mission of the innovation program.

According to the conceptual model of public administration, the main goal of public authorities and the local government itself, according to most experts, is to improve the quality of life of the population of the region (country). At the same time, the value of the complex indicator of the quality of life of $K_{S}$ is calculated on the basis of the analysis of a set of criteria grouped in the relevant areas. To such areas for the implementation of the research goal, it is proposed to include the quality of the population, security, infrastructure and income level.

As stakeholder management is invited to consider three participants in the innovative program - the University, state bodies and business structures.

The participants form a triple helix system, which we will call the system "U-S-B".

The object of management is the process of innovation in the framework of the innovation program.

In this situation, the mission of the innovation program is divided into three parts within the triple helix interaction "U-S-B" - the goal of improving the competitiveness of the University, the goal of profit, the goal of improving the quality of life of the population. The interdisciplinary approach is considered as the theoretical basis of the innovation program management. 
By analogy with physical objects, the development of the $j$-th organization takes part in the implementation of the innovation program, represents the movement of a material point from the actual place of expectation to the desired in the virtual space formed by the parameters of its strategic goals. In other words, if in the space of strategic goals $\{X ; Y ; Z\}$ the current state of the organization corresponds to a point with coordinates $\left\{X_{0} ; Y_{0} ; Z_{0}\right\}$, and the desired $-\left\{X_{1} ; Y_{1} ; Z_{l}\right\}$, the path that the organization must overcome is:

$$
L_{j}=\sqrt{\left(X_{1}-X_{0}\right)^{2}+\left(Y_{1}-Y_{0}\right)^{2}+\left(Z_{1}-Z_{0}\right)^{2}}
$$

Based on these assumptions, we can offer a model for determining the mission of the innovation program.

Objective function:

$$
E=\sum_{j=1}^{J} \bar{L}_{j} \rightarrow \max
$$

where $J$ is the number of organizations included in the innovation program performers;

$\bar{L}_{j}$ is the fate of the distance to its "desired state", which is overcome by the $j$-th organization in the case of successful implementation of the innovation program.

Let the indicators of the goals of the participants of the innovation program are determined by the $P=\left\{P_{1} ; P_{2} ; \ldots ; P_{I}\right\}$, where $I$ is the number of indicators. At the time of initiation of the program, the values of the corresponding indicators are determined by the matrix $P_{i j}$ '.

The" desired " values of the strategic indicators form the $P_{i j}$ " matrix, and their values in the case of successful implementation of the innovation program - the $P_{i j}{ }^{H}$. At the same time, if the $i$-th indicator is not among the strategic ones for the $j$-th organization, then $P_{i j}{ }^{\prime}=P_{i j}{ }^{\prime \prime}=P_{i j}{ }^{H}=0$.

Then the value of the objective function will look like:

$$
E=\sum_{j=1}^{J} \sum_{i=1}^{I} \sqrt{\lambda_{i j} \cdot\left(\frac{P_{i j}^{H}-P_{i j}^{\prime}}{P_{i j}^{\prime \prime}-P_{i j}^{\prime}}\right)^{2}} \rightarrow \max ,
$$

where $\lambda_{i j}$ is the specific weight of the $i$-th criterion for the $j$-th organization.

The value of $\lambda_{i j}$ can be determined using the expert evaluation method or the ranking method.

The organization's resources act as limitations for this optimization task:

$$
\sum_{m=1}^{M} r_{m} \leq R_{m j} \quad \forall_{j}=1,2, \ldots, J
$$

where $r_{m}$ is the required amount of $m$-th resource in the $j$-th organization for the successful implementation of the program;

$R_{m j}$ is the available amount of the $m$-th resource in the $j$-th organization.

The achievement of the mission of the program from the position of the University is limited by the number of specialists capable of conducting fundamental and applied research. Also, as a resource constraint institutions of higher education are the possibilities of infrastructure material and technical support for research. The state restrictions relating to the financial capabilities of the country budgeting innovative programs. Business structures are limited by the production capacity of the enterprise, financial resources, the availability of appropriate raw materials and materials for the implementation of the innovation program.

Taking into account the specific weight of the target criteria of each participant of the innovation program in the model "U-S-B" is a change in the state of the control object in order to increase the competitiveness of the program.

To identify and evaluate the values of the innovation program, indicators of achievement of its values are established, as well as evaluation criteria to measure the progress of the program. As a result, stakeholders involved in the implementation of the innovation program have the opportunity to evaluate the expected results using these criteria.

To achieve the mission of the innovation program, it is proposed to implement the distribution of criteria for each of the participants of the innovation program in the "U-S-B" model as follows:

- for the University: $K_{l}$ - material and technical base for scientific research; $K_{2}-$ a contingent of highly qualified specialists; $K_{3}-$ a contingent of students; $K_{4}$ - the level of research work;

- for the state: $K_{5}$ - quality of the population; $K_{6}$ - security; $K_{7}-$ infrastructure; $K_{8}$ - income level;

- for business: $K_{9}$ - finance; $K_{10}-$ production facilities; $K_{11}-$ raw materials.

In order to determine the specific weight of each criterion, it is necessary to create a table in which the coefficients of the relative importance of one criterion compared to another will be introduced.

This coefficient is determined on a scale: 1 - equal importance of criteria; 3 - moderate superiority of one over the other; 5 - significant superiority; 7 - very significant superiority; 9 - very strong superiority; 2, 4, 6, 8 - intermediate (compromise) judgments. The table has a characteristic property of inverse symmetry.

The weight of the relative importance coefficients presented in Tables 1-3 is determined by the ranking method.

Table 1: The relative importance of criteria for the University model" $\mathrm{U}$ S-B " innovation program

\begin{tabular}{|c|c|c|c|c|}
\hline Criterion & $\mathrm{K}_{1}$ & $\mathrm{~K}_{2}$ & $\mathrm{~K}_{3}$ & $\mathrm{~K}_{4}$ \\
\hline $\mathrm{K}_{1}$ & 1 & 3 & 7 & 9 \\
\hline $\mathrm{K}_{2}$ & $1 / 3$ & 1 & 9 & 7 \\
\hline $\mathrm{K}_{3}$ & $1 / 7$ & $1 / 9$ & 1 & 2 \\
\hline $\mathrm{K}_{4}$ & $7 / 9$ & $1 / 7$ & $1 / 2$ & 1 \\
\hline
\end{tabular}

Table 2: The relative importance of criteria for the state in the "U-S-B" innovation program model

\begin{tabular}{|c|c|c|c|c|}
\hline Criterion & $\mathrm{K}_{5}$ & $\mathrm{~K}_{6}$ & $\mathrm{~K}_{7}$ & $\mathrm{~K}_{8}$ \\
\hline $\mathrm{K}_{5}$ & 1 & 3 & 7 & 5 \\
\hline $\mathrm{K}_{6}$ & $1 / 3$ & 1 & 4 & 3 \\
\hline $\mathrm{K}_{7}$ & $1 / 7$ & $1 / 4$ & 1 & 3 \\
\hline $\mathrm{K}_{8}$ & $1 / 5$ & $1 / 3$ & $1 / 3$ & 1 \\
\hline
\end{tabular}

Table 3: The relative importance of criteria for business in the U-S-B model of the innovation program

\begin{tabular}{|c|c|c|c|}
\hline Criterion & $\mathrm{K}_{9}$ & $\mathrm{~K}_{10}$ & $\mathrm{~K}_{11}$ \\
\hline $\mathrm{K}_{9}$ & 1 & 9 & 7 \\
\hline $\mathrm{K}_{10}$ & $1 / 9$ & 1 & 5 \\
\hline $\mathrm{K}_{11}$ & $1 / 7$ & $1 / 5$ & 1 \\
\hline
\end{tabular}

Based on the comparison, the calculation of the claim weights of the criteria is carried out. To do this, first determine the geometric mean of the numbers written in the strings:

$c_{i}=\sqrt[n]{a_{i 1} \cdot a_{i 2} \cdot \ldots \cdot a_{i n}}, \quad i=1, \ldots n$

where $a_{i n}$ is the criterion value; $n$ is the number of criteria.

The specific weight of the criterion is determined by the formula:

$\lambda_{i}=\frac{c_{i}}{\sum_{i=1}^{n} c_{i}}, i=1, \ldots n$

Considering the features of the triple helix model of interaction within the framework of the innovation program architecture, it is possible to distinguish the presence of a high degree of risk. Due to the fact that the innovative program has a phased nature, it is 
possible to stop the research at the time when the continuation of the work becomes impractical. However, for example, a University that has started fundamental and applied research is not interested in early termination of work due to receiving funds for its work. It turns out that the entire risk falls on the customer, that is, the business structure, for which these developments can not lead to the production of competitive product innovation and further incurring large losses

\section{Discussion of Results of the Application of the Method of Forming of Innovation Pro- gram Architecture}

Organizations want to function as open systems operating in highrisk environments and try to balance stability on the one hand, and flexibility, willingness to change to achieve a higher level of efficiency on the other.

If we consider the stage of fundamental and specific developments of the University, in this case, many projects can be presented.

However, the purpose of the University is to implement those projects, as a result of which an innovative product will be obtained, which will increase the competitiveness of the institution of any education.

This situation implies income from the implementation of project developments, as well as dividends from patenting the already obtained innovative product, which can be directed to new projects that will be implemented in the future by the organization of the triple helix model.

In this case, it is proposed to use a risk management system at each phase of the innovation program life cycle. This will allow for the distribution of responsibility for the results obtained at a certain stage among all stakeholders of the program.

If you previously completed the studies are appealing, further investment costs of innovative activities would be borne by corporate business structures. In this situation, the entire risk of getting a certain result from innovation falls on the business, which ultimately receives all the profits from the implementation of an innovative product. In this case, the state and the University, which invested at the initial stage, remain outside the system and do not receive any dividends. There are two main reasons for this problem. The first reason is due to the fact that the system of copyright protection in our country does not work, that is, the actual fee for the use of intellectual property is absent. The second reason is that, even if a patent is obtained at the initial stage, it does not indicate the benefits of the resulting development. This fact determines the absence of buyers in the business sector on the results of the research. That is, fundamental and applied developments become useless.

This situation causes an imbalance of the system, which leads to the loss of links between its elements - the University, business and the state, which, in turn, destroys the system of management of the innovation program.

Therefore, there is a need to build a clear scientific methodology, which should be based on the concept of management of innovative activities based on the use of a model of risk management between the state, University and business.

The use of program-based innovation management mechanisms has made it possible to make the following conclusion. The high speed of changes in external requirements to the results of innovative projects leads to the fact that the creation of temporary network organizations is effective for the implementation of innovative activities. Such structures are the offices of the innovation program management in the form of a Union of organizations involved in joint activities on the triple helix model.

Any basic innovation project will quickly become non-compliant if the approved schedule is not changed in time by adding or excluding additional types of work. Also, it is necessary to adjust the parameters of work and technology taking into account the risk management system with the approval of all participants of the innovation program. These steps will ensure coordination in the program-oriented management of innovation.

Examples of implementation of mechanisms of client-oriented management of organizations are given in the study [17]. On the basis of these mechanisms in the [18] created a project management office.

In the process of implementing the innovative program is essential to the creation of the organization that will perform the information collection, data processing on the implementation of the program among all its members. The main purpose of this structure is to encourage stakeholders to engage in a constructive dialogue and effective interaction within the framework of the program.

The problem of managing an innovation program is to ensure the participation of all stakeholders in its implementation. To solve this problem, it is proposed to create an office for the management of an innovation program by analogy with the corporate Council of Directors with the participation of stakeholders (Fig. 4).

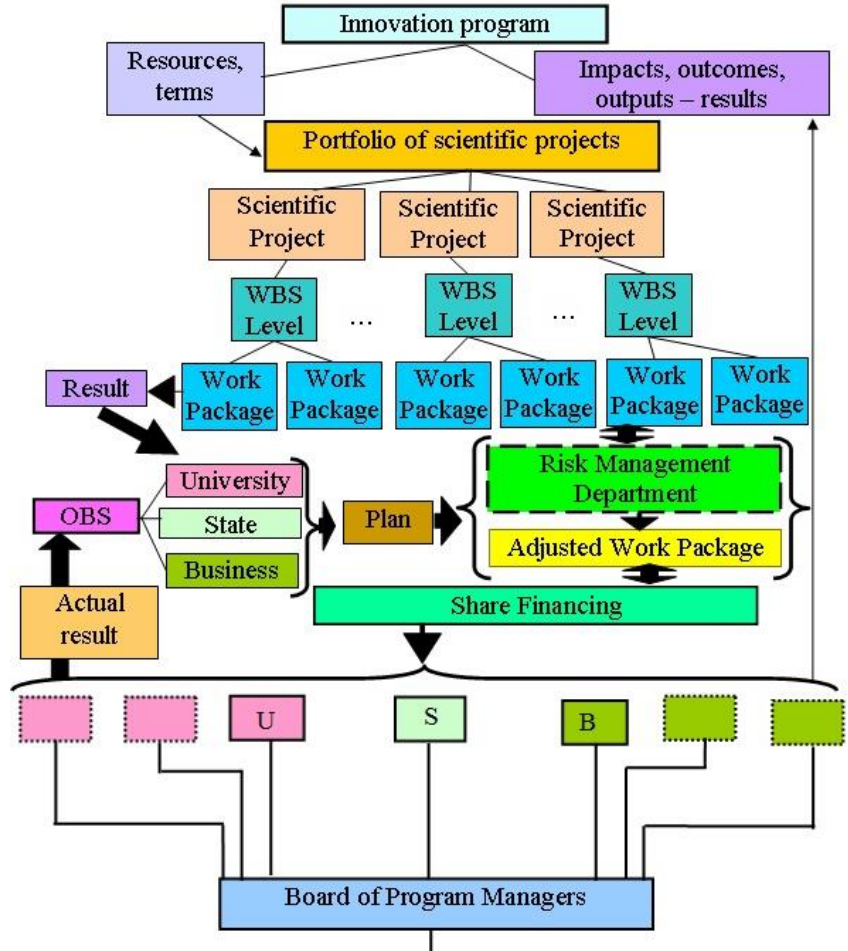

- forms the architecture of the program and selects the executors of
individual projects;
- calculates the total budget of the innovation program and determines the
contributions of the participants;
- calculates the risk of the program and approves the timing of the stages;
- monitors and controls the implementation of the program;
- decides on expediency of elongation of works at points of bifurcation.

Fig. 4: Model of the Office of Innovation Program Management in the Triple Helix System "U-S-B": WBS - Hierarchical Structure of Works; OBS - Organizational Structure of the Triple Helix System; U - University; $\mathrm{S}$ - State; B - Business

The purpose of introducing corporate mechanisms is to take into account and harmonize the interests of different groups of participants who are involved in the innovation program.

The program management office is the main analytical and coordinating unit, which is engaged in planning the program, managing its implementation, collecting information about the course of the program implementation. Also, the program management office develops proposals for solving the emerging problem situations, develops a plan of corrective actions necessary to balance the interests of stakeholders on the basis of the risk management system.

Thus, the program management office carries out the process of planning communications within the program. The purpose of the 
communication planning process is to ensure effective information exchange between the program stakeholders.

The mechanism of management of the innovation program is based on the vertical corporate structure of interactions, represented in the form of the Board of managers and the office of management of the program. Members of the Board of managers are representatives of universities, businesses and government agencies.

The projects that make up the innovation program are interdependent and interact in a complex way. In the management of the innovation program, in addition to the coordination of resources, timing and quality, the objectives of individual projects are coordinated with the mission of the program.

The use of the analogy with the Council of Directors is explained by the real possibility of predicting the impact of changes in one project on the implementation of a number of dependent projects in the program. When managing an innovation program within the proposed office, it is possible to track the chain reaction in al projects and the program as a whole when any changes occur. In case of conflict situations between the participants of the innovation program, threats in obtaining social and economic effect from the implementation of the innovative product, the office of the program solves the existing problems taking into account the risk management system.

The innovation program management office is developing a strategy to achieve the mission of the innovation program.

The composition of the Board of managers includes heads of organizations and enterprises in the "U-S-B" system, who participate in the innovation program.

One can draw an analogy with the internal Directors, who perform the function of monitoring the interests of all participants. An effective system of corporate governance ensures that the Board of managers fulfils the main duty in making the most important corporate decisions when implementing the innovation program.

If you have an idea for the implementation of a certain innovation program, at the initial stage, the distribution of the relevant costs should be carried out. This distribution is carried out between the three participants of innovation activities - the University, business structures and government bodies on the basis of determining a specific share in the total budget of the innovation program. In the same way there is a distribution of costs (and therefore risks) to the relation at performance of the further stages of the innovation program.

Based on the method of creating an office of management of the innovation program, taking into account the architecture of the program, it is possible to carry out the allocation of costs to the participants of the U-S-B system within a certain stage of the innovation program.

It should be noted that an important structural element of the office of management of the innovation program is the Department of risk management.

If the analysis of the results of the innovation program at a certain stage proves an increase in the level of risk, the risk management Department should carry out the following activities. One option is to suspend the innovation program at a certain stage. Another option may be to find rational mechanisms to compensate for risks. Such mechanisms include insurance, allocation of a range of conscious risks that the organization is ready to accept, performs innovative activities, and risk sharing among the participants of the innovation program.

\section{Conclusion}

1. On the basis of the methodology of project and program management, the concept of the innovation program was clarified. The result of innovation program management is the achievement of a single mission to obtain socio-economic effect from the implementation of the results of innovation (innovative product). The object of management is innovation. The subjects of management are universities, business structures, state bodies. The analysis of the GPM Global P5 standard allowed to formulate the model of life cycle management of the innovative program in the triple helix system "University-State-Business" (U-S-B) on the basis of modern international methodological foundations of program management of innovative activity. The result of management is the achievement of order, sustainability and development of the system of innovation activities according to the set goals.

2. To improve the efficiency of management of the innovative program, the program architecture was created. The proposed method of creating the program architecture allows to take into account the interests of all stakeholders (University, business and government) in the management of the program. The model of management of the innovative program allows, in contrast to the existing management models, to implement the division of the goals of each participant of the triple helix system "U-S-B". The achievement of certain strategic goals by the participants of the innovation program changes the state of the object of management which is characterized by an increase in the effectiveness of innovation in the implementation of a single mission of the innovation program.

3. On the basis of the proposed architectural model, the office of management of the innovation program in the triple helix system "U-S-B" with the organization of the risk management Department was created. The proposed method of creating an office of innovation program in the system "U-S-B" provides consistent and transparent management with the risk management methodology. Management within the program office is carried out from the structure of innovative processes, projects, current distribution of powers and responsibilities of "U-S-B" participants of the target program of transformation of strategic goals of the University, business and the state.

\section{References}

[1] GPM Global P5 Standard for Sustainability in Project Management V.1.5.1.

[2] Karpov A. O. (2017) Modern university as the driver of economic growth: models and missions. Issues of economics, 3, 58-76.

[3] Official site of the State Statistics Service of Ukraine. URL: https://www.ukrstat.gov.ua/

[4] Communication from the Commission to the Council, the European Parliament, the European economic and social committee and the committee of the regions «Innovation policy: updating the Union's approach in the context of the Lisbon strategy» (Brussels, 11.3.2003 COM(2003) 112 final.

[5] Bushuev, S. D., Bushueva, N. S. \& et. al. (2011) Creation and development of competitive project-oriented high-tech enterprises. Nikolaev: Torubary E.S., 260.

[6] Bushuev, S. D., Bushueva, N. S., \& Jaroshenko, R. F. (2012). Harmonization models property development programme in turbulence environment. Management of Development of Complex Systems, 10 9-13.

[7] Rudenko, S., \& Andrievska, V. (2016). Concept of project selection and its formalization in the absence of complete information. Eastern-European Journal of Enterprise Technologies, 2/3 (80), 4-10. DOI: https://dx.doi.org/10.15587/1729-4061.2016.65618

[8] Bushuyev, S. D., Bushuyev, D. A., Rogozina, V. B., \& Mikhieieva O. V. (2015). Convergence of knowledge in project management. Proceedings of the 2015 IEEE 8th International Conference on Intelligent Data Acquisition and Advanced Computing Systems: IDAACS, 496-500.

DOI: https://dx.doi.org/10.1109/IDAACS.2015.7341355

[9] Tanaka, K. (2014). The integration of engineering and program management with the marine economy. Shipbuilding And Marine Infrastructure, 1 (1). https://dx.doi.org/10.15589/smi20140108

[10] Piterska, V. M., Kramskiy, S. O. (2017) Methodological basis of innovative project-oriented organizations' management. Management of the development of complex systems, 30, 11-20.

[11] Piterska, V. M. (2016) Using of the project-oriented approach in the innovative activity management. Bulletin of National Technical 
University "KhPI", 1 (1173), 35-42. DOI: https://doi.org/10.20998/2413-3000.2016.1173.7

[12] Piterskaya, V., Bokareva, M. (2013) Energy model of the projectoriented organization value management. European Journal of Enterprise Technologies, 10 (61), 199-202.

[13] Donal O'Connell (2011) Harvesting External Innovation. Managing External Relationships and Intellectual Property, 21-26.

[14] Eveleens, C. (2010) Innovation management; a literature review of innovation process models and their implications. Working Paper HAN University of Applied Sciences, 23, 112-121.

[15] Itskovich, G. (2010) Triple helix. Universities-Enterprises-State. Innovation in action. GUSUR, 238-245.

[16] Kolesnykova, E. V., \& Fen, M. (2014). Aspects of practical management of the image of an educational institution. Information technologies in education, science and production, 2 (7), 216-227.

[17] Fesenko, T., Shakhov, A., Fesenko, G., Bibik, N., \& Tupchenko, V. (2018). Modeling of customer oriented construction project management using the gender logic systems. Eastern-European Journal of Enterprise Technologies, 1/3 (91). 50-59. DOI: https://dx.doi.org/10.15587/1729-4061.2018.123124

[18] Fesenko, T., Shakhov, A., \& Fesenko, G. (2017). Modeling of maturity of gender-oriented project management office. EasternEuropean Journal of Enterprise Technologies, 5/3 (89), 30-38. DOI: https://doi.org/10.15587/1729-4061.2017.110286 